\title{
Sciendo
}

\section{Growing Appetites and Hungry Subjects: Addicts, the Undead, and the Long Arc of Theory in Western Social Science}

\author{
A. JAMIE SARIS \\ Department of Anthropology, \\ Maynooth University, Ireland \\ ajamie.saris@mu.ie
}

\begin{abstract}
This paper explores the Western philosophical idea of "appetites" through the lens of "addiction." I begin with a brief ethnographic description of a woman whose subjectivity seems to emerge only in the play of her unmanageable desire for various pharmaceuticals. In other words, she is a self-described "addict." I then look at the relationships between addicts and the undead, especially vampires and zombies, who are seemingly enslaved to their appetites. This leads me to an analysis of the centrality of what I am calling "recursive need satisfaction" in much of Western (especially Anglophone and Francophone) Social Theory that, I argue, relies on a particular understanding of "appetite" in establishing the political-economic subjectivity that lies at the heart of market-oriented state. This same understanding also pushes this formation in a specific historical direction of increasing growth and organisational and technological complexity. As a globalised Western society in the last few decades has become ever more anxious of its place in the world, its impact on various interdependent systems, and the validity of the grand récits that served as its charter, such growth and complexity have emerged as objects of anxiety, even apocalyptic fear, and the terms "addict" and "addiction" have seemed ever more useful for modelling these concerns. I end with some reflections on how we use both zombies and addicts to think through some of the same issues of unchecked and damaging consumption.
\end{abstract}

KEY WORDS: addiction, appetite, crisis, social theory 


\section{Introduction}

My postdoc and I met Anna [a pseudonym] in several times in 2009 during a project funded by a Local Drugs Task Force on changing patterns of drug use in a Dublin neighbourhood (O'Reilly and Saris 2010). At that time, Anna was 36 year-old 'in treatment' for opiate dependency. Originally from Britain, but resident for much of her life in Ireland (almost exclusively in Dublin), she had been on prescription benzodiazepines and SSRIs for agoraphobia and anxiety attacks since late childhood. She also started to use and abuse heroin in her early twenties. And, like most of the consultants in my work in this field, she would also use a variety of other substances, based on logics of both pleasure and amelioration of some of the stresses of living.

We met Anna at an in-patient treatment facility, after having gained permission to sit in on some of the group work that occurred in that setting. We found Anna to be a very good collaborator - intelligent, articulate and engaged. Although when (mostly) we finally began intensive work with this group, initially, Anna was absent, as she had had taken two overdoses of prescription pharmaceuticals within the one week between our first informal meetings and the beginning of group therapy. We later discovered that these were classified as suicide attempts by her therapeutic team. Nonetheless, while continuing to be reticent "in group", Anna was very relaxed in more one-to-one situations, even sharing with us some of her demo songs and poetry.

The traditional tack for ethnographic analyses at this point would be to better flesh out some of Anna's life-history and her social and political contexts, that is, assuming the who of Anna and discussing some of the whys of her (seemingly poor) choices. Anna, in other words, would be assumed to be at least a potentially stable discursive platform, that, all other things being equal, should be the author of her appetites rather than their victim. Indeed, it is this gross imbalance between Anna-as-potentially-rational-subject and Anna-being-consumedby her-appetites that places her in various apparatus of knowledge-power, such as the criminal justice system, a treatment facility, or, indeed, a research project. On this basis, other factors, such as childhood trauma, structural violence, and gendered inequalities, would usually be invoked to "explain" such an unhappy outcome as entering a state of "addiction", never mind Anna considering the possibility of self-harm. 
I was struck by something else in our interactions with Anna, however - how conversant she was with the modern language of addiction and, more importantly, how thoroughly her embodied understandings of self were rooted out of the play of her (seemingly) uncontrolled and (apparently) self-disabling appetites. She had no trouble taking on the label "addict", and she discussed the recursive quality of her needs in very objectified terms.

[The doctor had me on] Prozac and things like that. They put an awful lot of weight on me, which lowered my mood even more. I was putting on so much weight my doctor was convinced I was bulimic, so he trebled the dose [laughs], so I put on even more weight. There is proof now that [those medications can] cause suicidal ideation, so I think that was part of it, and I'm naturally an impulsive and compulsive person, so I used to just turn off; my conscious mind would just turn off, and I'd have just one thought in my mind: "go off and take pills [laughs].

Anna is being treated for a combination of depression and anxiety, the commonest co-morbid diagnosis with "addiction", yet she is still taking heroin (when she can get it), despite being on methadone. She also consumes hash and illegally-gotten benzodiazepines regularly, while being told by her doctor to take something that (presumably) is dealing with the root cause of her exorbitant and prohibited appetites, that is, SSRIs to treat her depression. Meanwhile, both Anna and her doctor toy with a diagnosis of bulimia, another form of recursive and disabling hunger. All this because Anna is in quasi-coerced treatment as mandated by the Drug Courts with the threat of a custodial sentence over her if she fails to comply. The greatest irony of all it seems to me is how the appetites seem to have no focus here, or, better put, it is only in the play of uncontrolled appetites that something like a subject seems to emerge within this exchange, including (quite disturbingly from the point-of-view of anthropology as a humanistic discipline) an appetite for self-destruction.

\section{Productive Appetites}

While Anna's subjectivity seems elusive, her body, specifically, its appetites, are overproduced, the wobbly flywheel of Anna's existence. These appetites have entangled Anna in at least two main state and market configurations, both of which are economically and theoretically productive. The first is the profitable circuit of prescription pharmaceuticals and treatment modalities (see Patryna, Lakoff and Kleinman 2006). Ironically, Anna has configured herself as "addicted" to one of the most successful examples of such drugs (Prozac). Despite the recent battering their reputation has endured of late (e.g. Healy 2004), 
the SSRIs are very widely prescribed for addictive behaviour, and Prozac itself is still a byword in the industry for the almost perfect combination of perceived efficacy, novel marketing, and sheer profitability (see Saris 2011; Metzl 2003). Leaving to one side the ontological status of addiction for the moment, if the SSRIs are eventually tagged with this label (or the more ambiguous one of "dependency producing"), then they would be in a long line of psychotropic "wonder" drugs, such as Valium, to experience such a fall from grace (van de Geest 1996). Of course, Anna is also part of a second configuration of the state and the market, the circuit of illegal drugs, which implicates her in yet another profitable and globalised trading network, but one that the state has prohibited. This circuit connects Anna to primary producers as far afield as Afghanistan and South America and embeds her in an international production-distribution-consumption system that is almost breath-taking in its protean flexibility and occluded complexity.

In this sense, Anna's brain-body is a node connecting high-tech, professionally administered knowledge and techniques, global circuits of commodity production and consumption, classic exercises in sovereignty, such as guarding borders against contraband (with, it must be admitted, only indifferent success) and marking out the deviant from the normal citizen (and within the category of deviant, separating the salvageable from the unsalvageable). In her spare time, as it were, Anna also graciously contributes to another less salubrious (and arguably less respectable) circuit of knowledge production - my research and writing. Anna is, in short, a very busy woman precisely because of her hypertrophied appetites and the interests (economic, intellectual, and governmental) that have grown up around them.

Thus, if Anna appears to be the victim of her appetites, which in turn potentially victimize others if only through her support of some networks that are, at certain times, frankly antisocial, then it must also be granted that, through her appetites, Anna and her ilk keep a lot of the world going. To cater for them entire networks (not all of them legal), but some of them global in scope, have emerged. And, while Anna's psychiatrist, her addiction counsellors, her dealers and I will probably never meet in the same room, we are all strangely (and firmly) connected to one another through the profusion of her appetites.

\section{Unproductive Appetites}

Anna's story came back to me a few years later when I was fortunate enough to have won a Senior Fellowship at the Internationales Forschungszentrum Kulturwissenschaften (IFK). There a scholar of photography mentioned an exhibition she had attended the year before in 
2012 and in which she thought I might be interested. The gallery had featured a project by Roman Sakovich titled, Half. In this series of portraits, Sakovich photographed subjects in the studio "normally", then a second time using make-up to simulate the "ravages of drug abuse." Finally, he combined the pictures, in order to "explore the outsiders' superficial judgment of the same person before and after drug abuse." This technique results in temporally stereoscopic images, as if only half of Dorian Gray's picture were protected from the visual ravages of his sins (see Figures 1,2).

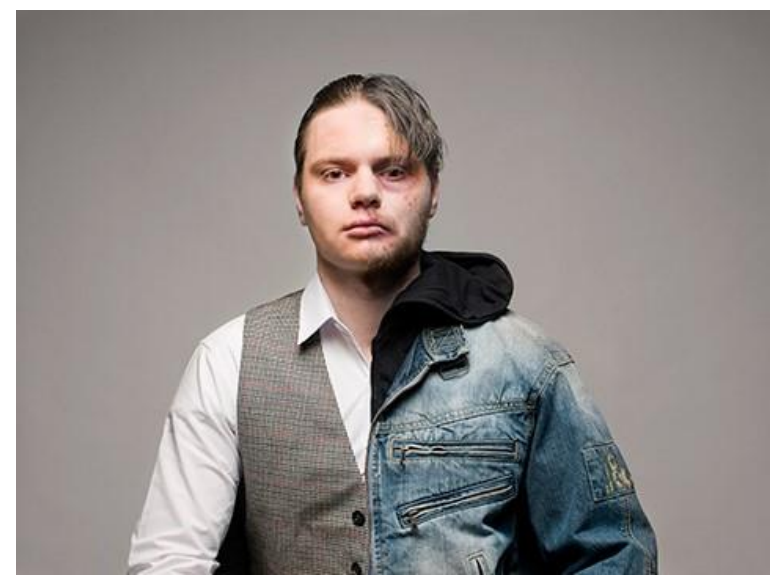

Figures 1 and 2: https://www.romansakovich.co.uk/portfolio/half

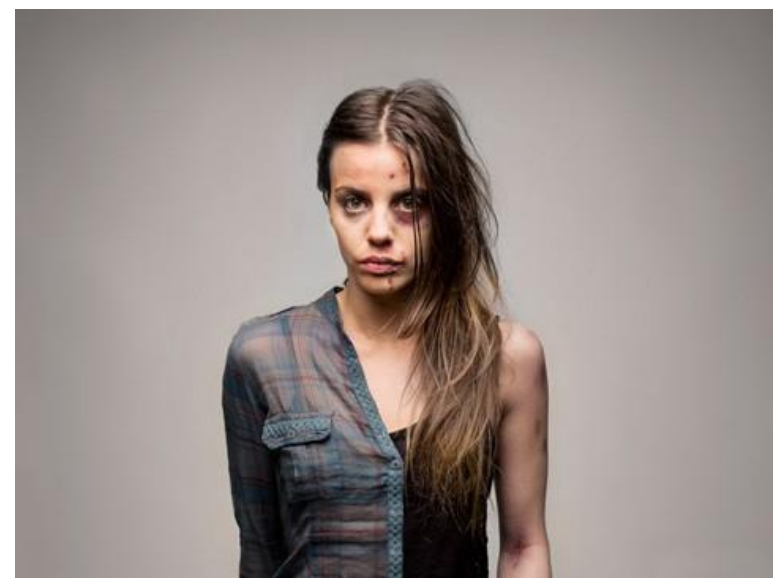

I dug up Sakovich's work on the Arts website "Feature Shoot", where it had received mixed reviews over the intervening 18 months, with many critics in the Comments Section 
expressing discomfort with the use of what they called a "Zombie Aesthetic" to show the difference between the two "halves". Many of these, somewhat missing Sakovich's point, felt that this trivialized addiction as a serious medical condition, while others more or less praised the equation "addicts = zombies", as, to their mind, addicts seem to have descended to a lower state of being anyways, so they were "like zombies." Few critics pointed out that the genre of before-and-after photos of celebrities in their decline had long since established themselves as a staple of the Internet, such as this one of Gary Dourdan (formerly of the popular television franchinse Crime Scene Investigation) (see Figure 3).

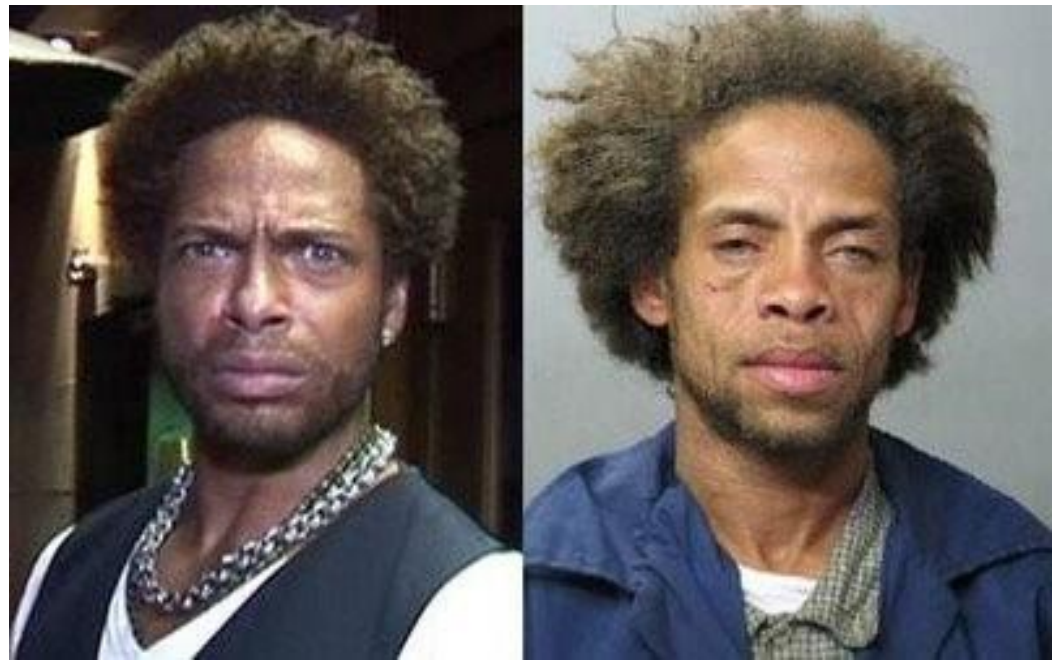

Figures 3: Gary Dourdan (http://chucks-fun.blogspot.com/2016/03/addiction-it-does-body-bad-27images.html)

Such photographs seem all but indistinguishable from the first two stages of Sakovich's work. The juxtaposition of such images tends to be connected to morality tales of erstwhile celebrities falling from the heights of fame and fortune (often under the influence of drugs), in the process receiving their comeuppance for being rich and high-living (and out-of-control) for at least some part of their lives (thus, a very unflattering police 'mug shot' is generally preferred for the "after" photo).

I had, of course, heard people in Dublin with whom I had been hanging out referred to as "zombies", even, occasionally as both humour and critique amongst themselves. It is certainly not a friendly term in the contexts in which I had recorded it, but it struck me as less rancorous and aggressive than "junkie" which contained for most of them a serious moral judgement. Nonetheless, I found myself thinking of Anna when I paged through Sakovich's 
work, and there I began, although I did not then know it at the time, a now oft-interrupted, multi-year think-through of why "zombies" and why now.

\section{Structure of the Argument}

To explore these directions, I do the following. First, I examine the idea of appetite in Western orderings of being human, alongside the emergence of the modern understanding of addiction in a chronology that also includes certain artistic creations of creatures that are very hungry for us, that is, the undead, specifically vampires and zombies. While, in some sense, stories about such eldritch creatures are very old, their modern versions develop surprisingly in lock step with the emergence of addiction as a medical category and its subsequent expansion some decades later. ${ }^{1}$ I then move from this overlap between pathologized appetites and their servicing by normalizing structures to an analysis of the centrality of what I am calling "recursive need satisfaction" in much of Western (especially Anglophone and Francophone) Social Theory since the Enlightenment, which, I argue, relies on a particular understanding of "appetite" (both borrowed and heavily modified from Classical sources) in establishing the political-economic subjectivity that lies at the heart of the market-oriented state. This same understanding also pushes this formation in a specific historical direction of increasing growth and developing organisational and technological complexity. However, as a globalised Western society in the last few decades has (ironically) become ever more uncertain of its place in the world, its impact on various interdependent systems, as well as the validity of the grands récits that served as its charter, such growth and complexity have emerged as objects of anxiety, even, occasionally, apocalyptic fear. Finally, as a way of marking out such anxieties, I come back to literary and artistic forms that embody uncontrolled appetites.

\section{Hungry Subjects}

The "zombie" and the "addict", it seems to me, are connected through a cultural judgement of the ways that appetite and rationality work in the life of the subject. While theories of

1 This overlap has been fruitfully developed in some Cultural Studies work, such as Zieger 2008. See also the various contributors to Weinstock 2020 and Scott 2007. 
addiction are manifold - and the ontological status of the category is routinely elaborated, modified, or even denied - the basic understanding of both addiction and the addict is still widely agreed upon. ${ }^{2}$ Addiction is an embodied appetite for something whose consumption simply calls forth more of the same need, usually in increasing amounts, generally with damaging consequences for subjects (and their behavioral environments), who then become "addicts". As the late American comedian, Robin Williams, put it in one of his stand-up routines: "When I took cocaine, I felt like a new man, and the first thing that new man wanted was more cocaine!" The defining qualities of these appetites for the "addict" in both Diagnostic and Statistical Manual of Mental Disorders (DSM) and International Classification of Diseases (ICD) boil down to powerlessness with respect to their control and unmanageability within the context of their lives (e.g. Goodman 1990).

The last fifty years or so, of course, has also seen a veritable explosion of popular interest in, and professional knowledge about, addiction. This state has emerged as an object of moral panic, as a protean biopsychosocial medical category, and as a model of, and for, politicaleconomic anxieties. We now acknowledge multiple (perhaps hundreds of) objects, desires, and activities that can emerge as "addictive" appetites for at least some subjects. Increasingly, we look to cutting edge neuroscience to "unravel" the complex biology of addiction, even as other scholars in other registers talk about addiction as a disease of the spirit as much as the brain/body. At the same time, we model an increasing number of global political anxieties (such as Climate Change) under this same rubric (e.g. our society's addiction to hydrocarbons becoming an existential danger to our way of life). ${ }^{3}$ Thus, my initial observation is a simple one: all of these levels see a connection between addiction and appetite, and this connection

In 1997, Alan Leshner, at that time Director of the National Institute on Drug Abuse (NIDA) published a significant article, "Addiction is a Brain Disease, and It Matters," in Science (Leshner 1997). This work inaugurated a moment of increasing research funding, published outputs, and what we might call "translational" productions (see Nora Volkov's videocast Addiction: A Disease of Free Will), announcing in more popular forums the conquest of "addiction" by increasingly sophisticated brain research and imaging techniques. It is beyond the scope of this paper to analyze this body of work, still less, to offer a final word on the ontological status of addiction. I merely note addiction's increasing force as a metaphor for social disruption and crises, its continuing ramifying applicability to individual psychosocial problems, and the persistent traces of the metaphysical (spirit, higher power and the like) in most published sources on the condition. In this work, I want to trace the force of which addiction presumably marks the loss of control, i.e., appetite, as a means of understanding some of these issues.

3 One can quibble when this idea of a society being "addicted" to a substance became "common sense", but, in the case of the statement that "America is addicted to oil", one could do worse than point to George W. Bush's 2006 State of the Union Address where this assertion was made in a matter-of-fact way that caused little controversy in its reception (see Bumiller and Nagourney 2006). 
serves as a sort of operator to structure multiple anxieties, critiques, and sometimes even apocalyptic fears at different levels.

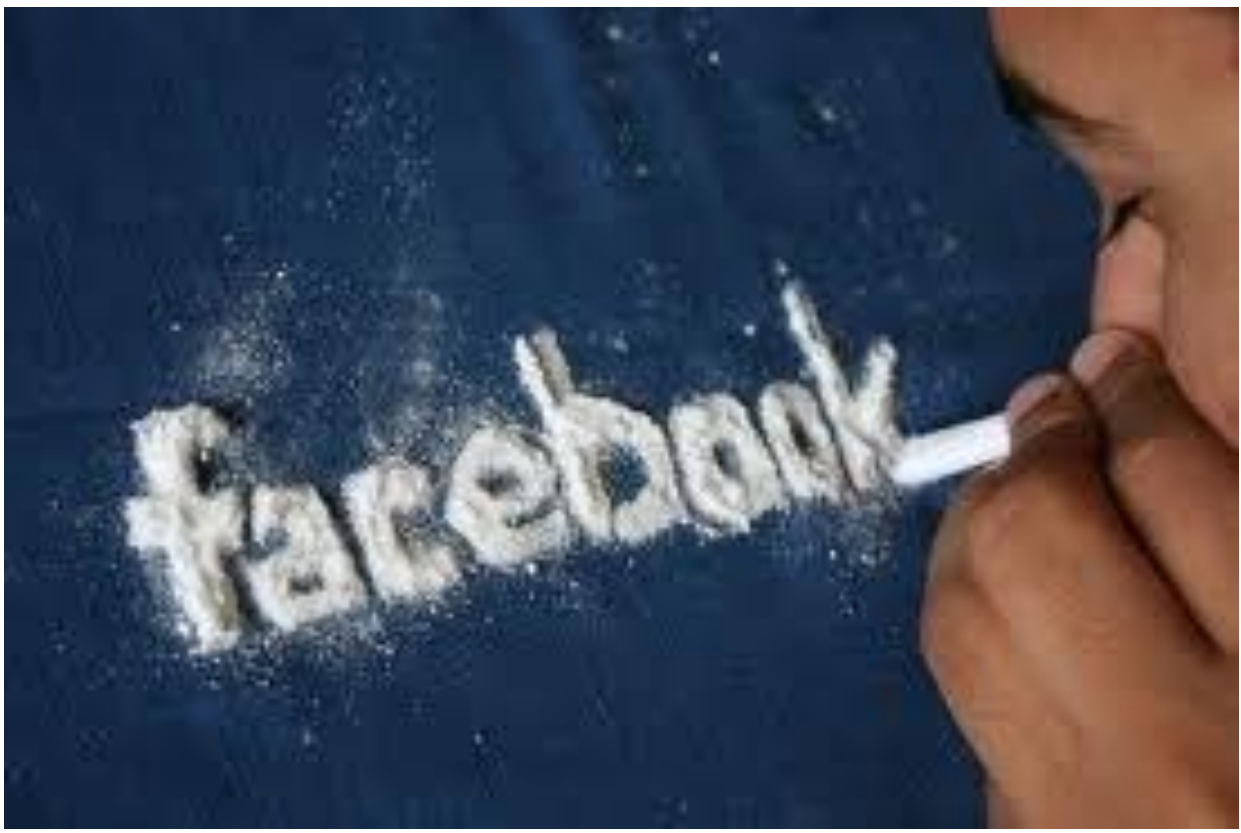

Figure 4: https://www.deviantart.com/gladiator656/art/Facebook-addiction-143022266

Nonetheless, through all the moral panics, the semantic space currently occupied by the terms addiction and addict remains stubbornly ambivalent. On the one hand, while we pity and censure the addict, and we fret about the social and economic costs of addiction, we are increasingly obsessed by the category and are willing, almost eager, to apply it ever more widely (e.g. Denizet-Lewis 2010). In the last few decades, for example, our concern has spawned entire research agendas, resulting in thousands of books and scores of scholarly journals. Indeed, so great has this archive become that it now supports specialized subdisciplinary historians writing different versions of how all this came to be (for a very approachable instance of this genre, see Courtwright 2001). On the other hand, we also use addiction in a wryly humorous fashion to model devoted, even passionate, interest in recursive activities. Indeed, it has become one of the main ways of understanding the passionate dissolution of the ego into something larger, and it can serve as a sort of insider joke that we share amongst ourselves about iterative activities connected (especially) to 
leisure pursuits that we end up taking very seriously indeed. ${ }^{4}$ In the last decade or so, for example, certain communication technologies that tend to dissolve the boundaries between work and play, public and private, and self and other, in a fashion, that we clearly enjoy, but with which we are not always wholly comfortable, have been readily modelled in this way.

\section{Appetite}

If we accept provisionally that appetites and addiction are conceptually entangled with one another, ${ }^{5}$ then perhaps bracketing the subject of addiction and focussing instead of the idea of appetite might be productive. Was I interacting with Anna's appetites a couple of years ago, a scientific voyeur of her demons, rather than a committed servant of a higher power trying to exorcise them? Can appetite be addressed outside of its subjects and objects? If so, is a historical ethnography of appetites possible, even useful?

These questions seem odd, but they improve upon acquaintance. A surprising number of "great thinkers", for example, have devoted loving attention to Appetite as such. Cicero, for instance, tells us appetitus impellit ad agendum [appetite impels [one] to action], centering appetites as fundamental to any discussion of life itself. In this respect, Cicero is heir to a long tradition in Western Philosophy, going back to Plato's tripartite psychology of man in The Republic and Aristotle's more binary understanding in The Nichomachean Ethics, that takes Appetite as a key to understanding both human life and society (see Lorenz 2006). In both Plato and Aristotle, appetite is the embodied source of, often irrational, desire that comes complete with a social version reflected in the desire humans have for admiration of their fellows (in Greek, the desire for kudos). These impulses move humans into interaction with

In Chapter 2 of The Globalization of Addiction (2008) Bruce Alexander tries to sub-script the various definitions of addiction with respect to compulsion and harm to subject and/or others. The term seems to resist such semantic parsing in real life. I argue in this paper that there is a theoretical infrastructure to such semantic complexity.

$5 \quad$ At least the preliminary case for this entanglement can be seen in the history of the pharmaceutical treatment of "addiction". Dole and Nyswander $(1967,1976)$ ran the first clinical trials for methadone to treat "opiate addiction" and then published the seminal papers reporting their (partial) success in this regard as well as proposing a model of a "metabolic lesion" as underlying "addiction" as a medical condition. Very quickly, though, "real" rather than metaphorical hunger, that is excessive eating leading to obesity, became an object of much Big Pharma research interest in this topic. From the early 1980s, the "Holy Grail" of this work was the hope that there might be something "like Methadone" to deal with hunger as such (and therefore obesity). This produced a veritable tradition of research, genealogically connected to Dole's Lab at Rockefeller University (for a popular history, see Shell 2003; Saris 2008, 2011). 
the world and one another. The dialectic balance to appetite in this thinking is "Reason" which in both models is charged with the control of appetite, partly through sheer denial, but also, crucially, through the cultivation of an "appetitive desire" for "the Good" (Lorenz 2006, $2-24)^{6}$

It takes no great insight to see that modern consumer capitalism is also very much entangled with understandings of appetite. In most contexts, for example, we valorise the capacity of our appetites, and consider both the goods that we develop to satiate them as well as their evolving quantity and quality a mark of the "good" life? Where else can our understanding of economic growth be located if not in expanding the number of consumers, and increasing the quantity and quality, of their appetites and desires? In this sense, we can take appetite as at least a privileged concept, in not the actual motive force, of "development" in our own (more or less "Western" ways) of comprehending "History" and "Society" (see Figure 4).

It is telling, therefore, that within a short period of time around the beginning of the $20^{\text {th }}$ century, a pathologizing of appetites in a novel term, addict, emerges alongside artistic creations who embody appetites that survive death in the form of undead beings who feed on humans. By the end of the $20^{\text {th }}$ century, out of control appetite appears in a variety of apocalyptic scenarios in fact and fiction. I argue that these musings of out-of-control appetites can be read as a sort of skewed reflexivity - our own social formation looking at itself through a glass darkly, a means of reflecting on the development of (and, as importantly, some of the crises in) the grands récits of Western philosophy and Social Science. ${ }^{7}$ In this way (pace arguments like Comaroff and Comaroff 2002; Stratton 2020) the undead, serve not just as a means of modelling the marginal in capitalist economies, such as economic migrants in the case of zombies, but as central axis to understanding how our social formation developed and currently functions.

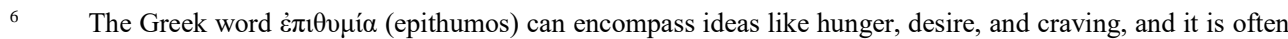
used negatively, as in lust. Most scholars of Plato seem to translate this word as "appetitive desire" which strikes me as unwieldy in English. I am using appetite in this sense, and while I focus on "hunger" in this work, I do not want to privilege unduly orality as such. I am indebted to the audience for my public lecture at Internationales Forschungszentrum Kulturwissenschaften in January 2014 for encouraging me to clarify this point.

$7 \quad$ Research on the social history of luxury has covered some of this same ground (e.g. Berg 2005; Berry 1994). Addiction as a result of the constitution and repression of pleasure has also been examined in a variety of Cultural Studies research (Sedgwick 1994; Zieger 2008). 


\section{Assemblages, the Undead and Addiction}

There are two sets of dates that seem crucial in this discussion. The first is 1897 (counted twice), when two entities (partially immaterial to be sure, but with truth-effects in the world), were not so much created, as structured into their modern form. In that year, the German firm, Bayer, patents Aspirin, ${ }^{8}$ solidifying a few trends in the late $19^{\text {th }}$ century. First, this patent inaugurates the modern pharmaceutical industry in a social-political sense (Bayer had been producing drugs since the mid-nineteenth century). A year later, Bayer also patents Heroin. By the late 1890s, the very profitable field of market-driven cures for human ills had assumed much of its modern form of pharmaceutical companies, with in-house research labs and marketing departments, delivering "effective" drugs to the public on which they enjoy an enforceable, if time-limited, monopoly (see Figure 5).

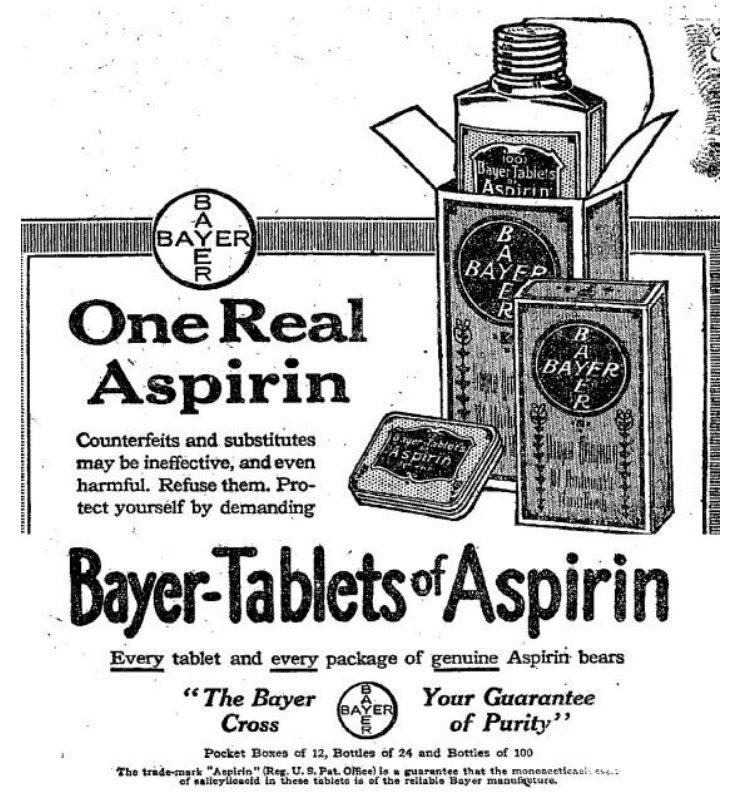

Figure 5:

https://upload.wikimedia.org/wikipedia/commons/thumb/c/c1/Bayer_Aspirin_ad\%2C_NYT\%2C_Februar y_19\%2C_1917.jpg/105px-Bayer_Aspirin_ad\%2C_NYT\%2C_February_19\%2C_1917.jpg

The first patent is taken out in Germany in 1897, which is subsequently rejected. The British patent is granted in 1898 and the US one in 1900. In 1898, of course, Bayer also patents Heroin. 
Of course, during that same period, corporate personhood is recognized in law in a series of landmark legal decisions, first in the US and then further afield. These two patented drugs also embody the ends of another trend, quite strong in North America, but present, too, in Europe, of regulating previously widely-available compounds into legal and illegal varieties (such as The Harrison Act in the US in 1914), while making certain professionals (i.e. allopathic doctors), the formal gate-keepers of the legal pharmaceuticals, all in the name of public safety. Now, of course, Aspirin is all but ubiquitous in everyone's medicine cabinet, while heroin is a persistent illegal "street drug", a scourge that has survived numerous attempts to eradicate it, yet still one that is still available to much of the world's population.

Also, in 1897, the Irish writer, Bram Stoker, publishes Dracula, creating the modern vampire. ${ }^{9}$ To do so, Stoker smooths out a rich and complicated tapestry of traveler tales and European folklore about evil spirits with a taste for living humans into a modern literary depiction of a lone aristocratic undead Übermensch, with a specific hunger for blood. In the story, Dracula migrates from an obscure corner of Eastern Europe in search of redder pastures in Britain. The vampire proves a formidable foe for a collection of characters representing the best aspects (at least in Stoker's view) of Euro-American history and society - from the idealized Victorian womanhood embodied in Mina Harker to the religious devotion and metaphysical lore of the venerable Dutchman Abraham Van Helsing to the youthful energy (and impressive armoury) of the American Quincey Morris (see Figure 6). Deploying all the modern technological advantages they can lay their hands on - from dictaphones to portable typewriters to cross-continental train travel - this original Scooby Gang, first, drives Dracula back to his Transylvanian homeland, then defeats him on his own turf, to be sure with some loss (poor Quincey dies), but with only a ripple of notice in the broader society. Polidori's The Vampyre (1819) and its republishing in France in subsequent years. In Polidori's version, though, the vampyre gets the girl (and, indeed, gets away), and the protagonist suffers a nervous breakdown at his own impotence to prevent the death of his sister. It is beyond the scope of this paper to analyze the differences between Stoker's and Polidori's creations, but, while Ruthven, the vampyre, has some recognizable attributes, it is clear that Stoker's Dracula is the template for nearly all subsequent vampire stories. 


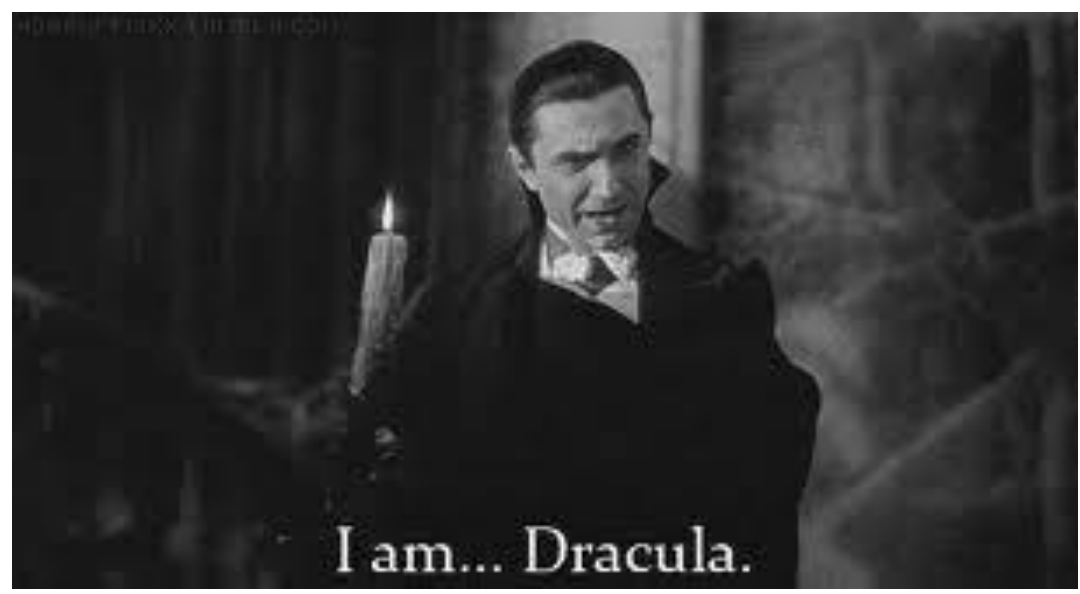

Figure 6: http://s2.favim.com/orig/28/bela-lugosi-dracula-subtitles-text-vampire-Favim.com-231645.gif

The next dates are separated by a decade. In 1958, JK Galbraith publishes The Affluent Society, in which he argues that an Economic Science based on scarcity is now obsolete and that consumption rather than production must be made central to modern economic thought. Crucially, he lays out a case that private wealth and consumption in the USA occurs at the expense of public spending and investment, and that this imbalance is both socially, environmentally, and economically perilous. Ten years later, in 1968, George Romero releases Night of the Living Dead, a story of corpses reanimated by that acme of technological modernity, a spacecraft returned to earth (see Figure 7). In the movie, these revived creatures (ironically only called ghouls in this movie) awake with an insatiable desire for human flesh. Their appetite nearly overwhelms everything that modern society has to throw at them. As the zombie franchise develops, moreover, it is clear that our society is really no match for this species of the undead - even when they are defeated, and something like order is restored, it is only at terrible cost. In the decade between Galbraith and Romero, the modern environmental movement is launched with the publication of Rachel Carson's Silent Spring (1962), inaugurating an historical moment when human consumption and technological virtuosity becomes a source of increasing anxiety (at least to some), predominantly in those places that are consuming the most resources in the most technologically sophisticated fashion. 


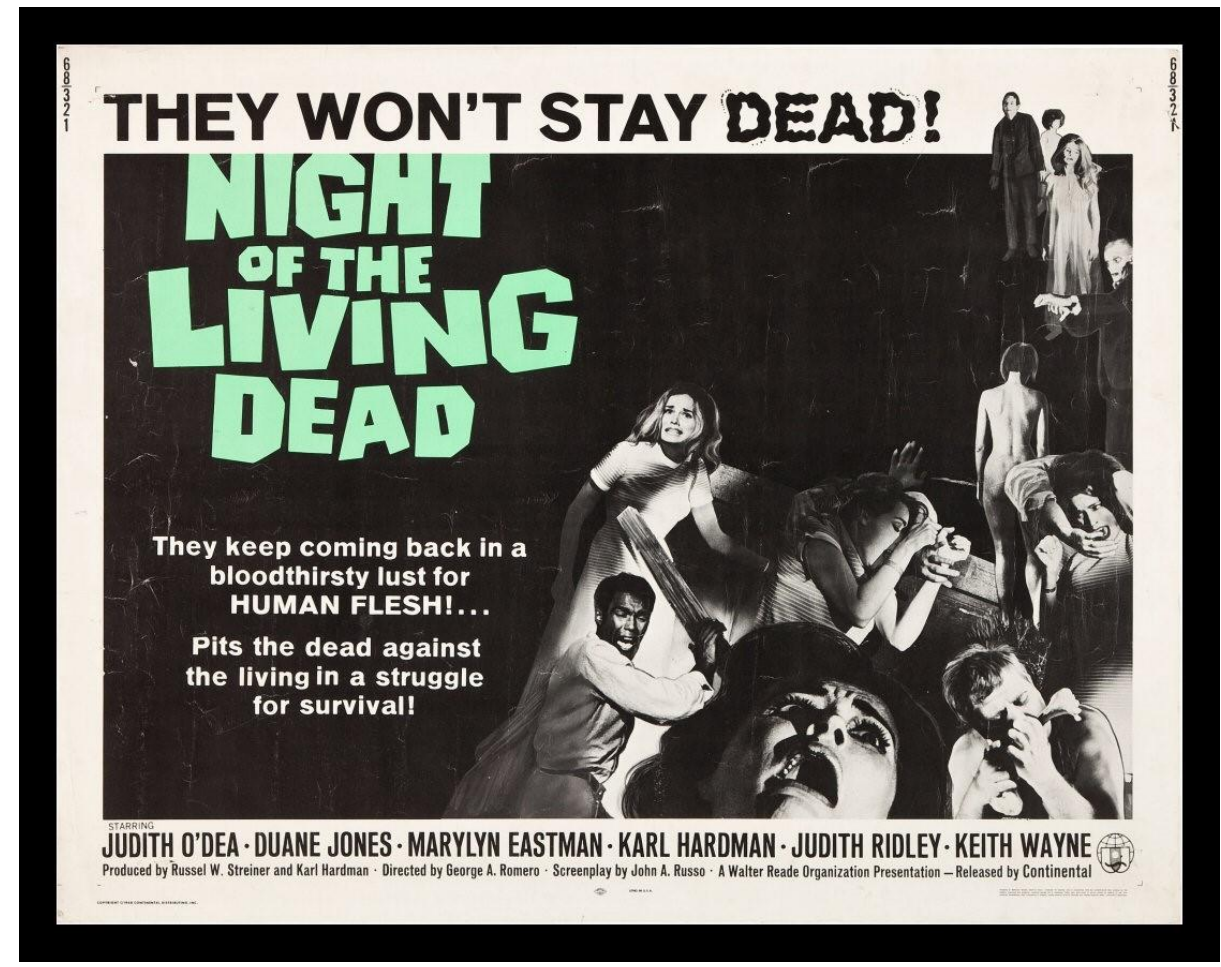

Figure 7:

https://drnorth.files.wordpress.com/2011/10/night_of_the_living_dead_poster.jpg?h=119\&w=150

\section{Addictive Subjects}

In between our two sets of dates, a novel medical category, addiction, assumes its modern usage in English, and a new form of subjectivity emerging from out-of-control appetites addict - is stabilised in English as a noun (it is only recognized as such by the Oxford English Dictionary in 1920). The prehistory of "addict" in English, as a participial adjective, as in "to be addict" and as an intransitive verb "to addict" (oneself), ${ }^{10}$ is completely usurped and all

10 Shakespeare (1599), for example, in Henry IV, Part II (Act 4, Scene 3) has Falstaff say: "If I had a thousand sons, the first humane principle I would teach them should be, to forswear thin potations and to addict themselves to sack." To addict (oneself), though, is clearly a conscious action. After listing the martial virtues 
but forgotten. Ironically, "to be addict" once meant to pledge oneself consciously to a person or to a cause, seemingly one of the highest expressions of will (Saris 2013). Of course, addict as a noun now marks out a semantic territory where the will has been lost, perhaps even banished forever, but something that still looks and (sometimes) acts like a human subject remains. This discursive move inaugurates a convoluted medical-moral conversation involving fundamental questions of what it means to be human - ideas about freedom and pleasure, appetite and restraint, of proper brain function and morally mindful choice, of the connections between the metaphysical and the material, and the relationships between the individual and the society - a conversation that is still ongoing.

By the late $20^{\text {th }}$ century, addiction is increasingly considered a serious condition - easy to find, protean in shape, and difficult to cure. It becomes serious business, with estimates of lost productivity to this condition now running into the tens of billions. It is also a source of considerable research funding - from work in cutting-edge neuroscience searching for deracinated "impulses" in the brain to clinical research (very often combining pharmacological, psychological, and spiritual eclecticism) through swathes of the social sciences interested in social and familial insults in the life history of people suffering from this condition, addicts and addiction are the object of intense scholarly scrutiny. My own research has in part been funded through such sources, and, consequently, I have had to produce work in terms, such as "addiction" and "treatment", even at times when it has been clear to me that these terms obscure as much as they reveal the lives of the people with whom I and my teams have interacted (Saris 2008, 2021). This framing of my work has itself been an object of some of my scholarly writing (e.g. Saris 2021). To put it as simply as possible: what has struck me in much of this research is the contradictions between the subjects with whom one is in dialogue in ethnographic work and the processes that have moved this individual into an apparatus of addiction and treatment, specifically when confronted with narratives that construct the subject through his or her subject position as "addict".

This is, of course, also the mirror that the addict holds up to the consumer in our current social formation - he or she possesses appetites to be catered for but of the wrong kind and/or in excessive quantity. Nonetheless, whether we like it or not, in the West, we have historically been quite proud of our (obscure and over-sized) appetites. To say that the Hegelian world historical process came to rest in 1989 with the fall of the Berlin Wall because of a tropical

that strong drink like the sherris (sic) and sack promotes in young men, the argument is (more or less), "Swear off the soft stuff and devote oneself to a real libation!", if you want to be a man. 
fruit is no doubt an exercise in gross simplification, but the old German Democratic Republic's obsession with the banana was legendary, so much so, that it became a ready resource for synecdoche and irony, what Friedrich $(1989,309)$ rightly calls "the politically explosive figures of speech". After Hungary and then the GDR began to issue exit visas in 1989, aphoristic stories of it being impossible for shops within a hundred $\mathrm{km}$ from the Border to keep bananas in stock began to circulate. The Cold War Triumphalism amongst (especially) American intellectuals in the wake of the collapse of Communism, such as Fukuyama's The End of History and the Last Man (1993), was built in crucial respects on the theoretical foundation of the superior capacity of the West (meaning the market-centred state) to both satisfy (and develop) appetites. In other words, the yearning for freedom and the yearning to consume was almost indistinguishable in the work of the proponents of an American-led globalization in the 1990s (see Friedman 2000, especially his novel suggestion that countries that adopted McDonald's did not go to war with one another).

\section{Western Social Theory as a Dialectic of Appetite}

The economic collapse of 2008 and (too) slowly increasing awareness of environmental crises of the past few decades has somewhat blunted the optimism attending a globalized consumer economy, yet it takes little reading to reveal how central appetites have been to Western understandings of history and society as they are codified under the logic of the market-centred state. Indeed, it is the assumed imbalance between the appetites-within and the-means-of-satisfying-them-without that undergirds the curious assumption at the base of much of Western Social Science. This is that human beings are, fundamentally, asocial, perhaps even anti-social. In the mid-seventeenth century, Thomas Hobbes, provides the charter for this idea in his seminal work The Leviathan (1651) (see Figure 8). Hobbes, of course, writes at the cusp of the emergence of the modern nation-state in Europe in the wake of the devastation of the Thirty Years War and the subsequent Treaty of Westphalia (1648). At this time, as Foucault observes in several places in his oevre, the Christian guarantee of divine right begins to fade, and a notion of sovereignty takes its place, laying the groundwork for the idea of political-economy, as well as the sciences of intensification of this construct that Foucault labels governmentality. Hobbes goes further than simply establishing a science of "politics" and "economics", however - he develops a veritable creation story, a scary before-time of Society and History, based on his own musings and life history, a smattering of knowledge about the world that European expansion had opened up to him, alongside his readings of some Classical sources (see Sahlins 2008). In Hobbes's story, of course, the first 
and primary interaction that humans have with one another is bellum omnium contra omnes, ${ }^{11}$ the war of all against all.

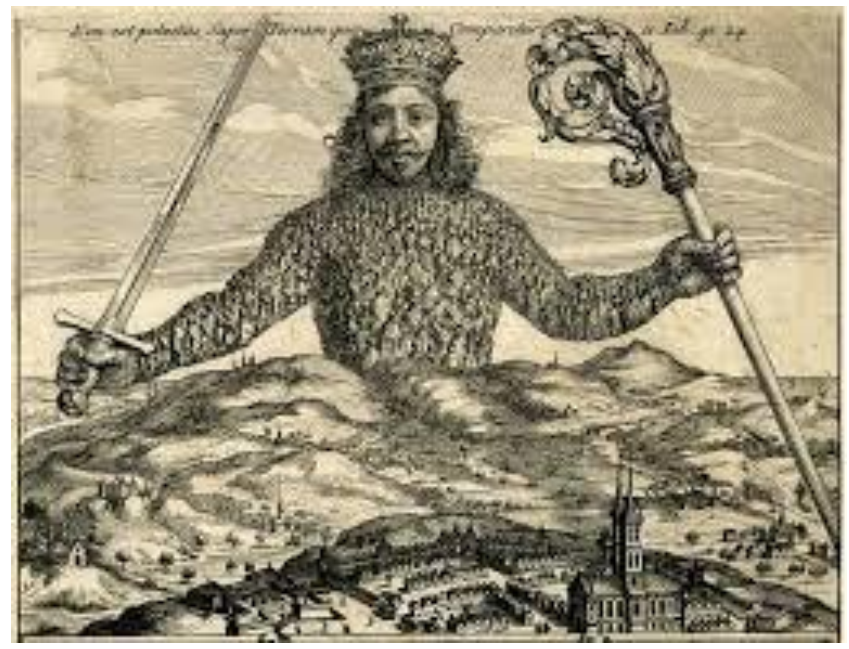

Figure 8: https://cdn-images-1.medium.com/max/1549/1\%2AGGcpBD_PzmCFmV36dk_fBQ.jpeg

Even so, while War in the state of nature may be the first interaction that humans have with one another, it is decidedly not the starting point of Hobbes's analysis. The main curiosity of The Leviathan as text about political power is that the first several chapters have almost nothing to do with anything like a modern understanding of politics: through a modern lens of disciplinary expertise, they appear unabashedly psychological (grounded, ultimately, in his understanding of physiology). A theoretical human equality is posited on the basis of there being nothing in the mind of man before experience. This tabula rasa is then written on by empirical engagement with the world, understood as a veritable mugging of the individual mind/brain suffered at the hands of an always/already natural order though the pathways we

11 There is a debate in the scholarship on Hobbes as to the nature of this state - in other words is it a thought experiment (something along the lines of his contemporary William Harvey was engaged in imagining the circulation of blood) or is it a rather bizarre history. There is no doubt that Hobbes sees the model of the individual in the State of Nature as theoretically prior to social interactions (otherwise the Leviathan loses its logical necessity), and, at times, he seems to further suggest the historical reality of this state through the odd references to what passes for the ethnographic record of the time, his reading of social breakdown in Classical sources, and his own sense of imperiled security (see Sahlins 2008). 
call sense. We are, therefore, limited in this sense of being at the mercy of the world. Sadly, Hobbes tells us that we are also suffering, as there are fewer good things than there are appetites chasing them. Thus, the Hobbsian individual is little more than a clockwork mechanism of appetites and capacities, with the former always exceeding their full satiation by the latter. This relationship impels the will to balance the equation as well as it is able (the ratio in rationality). Conceptual equality in our faculties then becomes rough political equivalence in the state of nature. In other words, without Law, no one is so strong as to guarantee his own security individually, nor is anyone so weak that a temporary alliance to deprive someone else of something good becomes inconceivable.

\section{Appetites and Reason}

The genius of the Hobbsian model of the Individual lies in its alchemical fusion of the rational and the a-rational. Appetites are non-negotiable and non-reasonable but they are also the impulse that drives a very capable rationalising impulse into an unfriendly world - first to suffer in the state of nature but then to move humans into History through the Social Contract - still pretty miserable, but at least with Security, and with some Industry and Progress as increasingly effective salves. Any resting point in the need-satiation cycle, though, is temporary. Felicity, according to Hobbes, is the satisfaction of desires and appetites, but, as he puts it in Ch 11, Felicity is necessarily always transitory:

[N]or can a man anymore live whose desires are at an end, than he whose senses and imaginations are at a stand. Felicity is a continual progress of the desire from one object to another; the attaining of the former, being still but the way to the latter [Leviathan Ch 11$]^{12}$.

Thus, despite Progress (and what we would later come to call "economic growth" and "technological development"), felt scarcity remains the constant companion of human beings, and, thus, the social bonds between people always remain tenuous.

This model of appetite, partial and temporary satiation, and development/growth has been a stable assumption of disciplines concerned with political-economy for centuries in the wake of Hobbes. To put it bluntly, nearly all subsequent Anglophone Social Science did not need to rewrite the Leviathan's 'psychological' chapters anew because they largely stipulated to 
them. This formula of the security of persons and property provided by the Social Contract, allowing the fruits of industry to be realised, which then allows new needs to develop, which then can be (provisionally) met became the acme of political and economic reasoning. This understanding is solidified by the canonisation of Adam Smith's Wealth of Nations (1788) almost a century and a half after Hobbes, or at least the parts of this work that are remembered - the Invisible Hand of the Market is generated by, and generates, a rational optimum in a vast collection of individual exchanges in pursuit of maximizing marginal utility in the satisfaction of individual needs (appetites). In this reading, a certain kind of Practical Reason, in Sahlins' words (1976), then emerges as a preeminent driver of History.

The fetishization of this part of Smith's work, however, hides the important role that arational appetites as such played in the emerging sciences of political-economy. Only a few decades after Hobbes (and almost a century before the Wealth of Nations), two authors, John Cary ${ }^{13}$ and Dudley North, both interested in what they start to call the science of "PoliticalEconomy", with a special focus on the Growth of Wealth, both publish the same paragraph (North in 1691 and Cary in 1695) highlighting recursive need satisfaction as central not just to every facet of human interaction, but also to History as such.

The main spur to Trade, or rather to Industry and Ingenuity, is the exorbitant Appetites of Men, which they will take pains to gratifie [sic], and so be disposed to work, when nothing else will incline them to it; for did Men content themselves with bare Necessaries, we should have a poor World. The Glutton works hard to purchase Delicacies, wherewith to gorge himself; the Gamester, for Money to venture at Play; the Miser, to hoard; and so others. Now in their pursuit of those Appetites, other Men less exorbitant are benefitted; and tho' it may be thought few profit by the Miser, yet it will be found otherwise, if we consider, that besides the humour of every Generation, to dissipate what another had collected, there is benefit from the very Person of a covetous Man; for if he labours with his own hands, his Labour is very beneficial to them who imploy [sic] him; if he doth not work, but profit by the Work of others, then those he sets on work have benefit by their being employed (North 1691, 27).

Indeed, it was the invasive success of a European Civilization based on this iterative and expansive relationship between appetites, industry and development, that, according to other

13 Reinhert (2011) in Translating Empire: Emulation and the Origins of Political Economy follows the ways that Cary's work is translated throughout Europe as emerging European nation-states seek to understand and/or emulate Britain's emerging economic might. 
methodological individualists, such as Herbert Spencer, was the guarantor of its globally privileged position, on the one hand, as well as its internal hierarchies of class, race and gender, on the other. Some voices may have insisted that, after leaving the state of nature, the state/market configuration based on "unnatural" needs was creating an ever more an unequal and degenerate modernity (Rousseau), while others were inclined towards a more tragic relationship between industry and appetites because of the unmanageability of the appetites of growing populations (such as Malthus), but the spiral of recursive need satisfaction leading to more needs, leading to an inevitable historical process was not significantly challenged in Anglophone social theory until the modern environmental movement, and even then only incompletely. From this perspective, Appetites emerge as the driver of history and individual Reason as a harried handmaiden, whose Trojan efforts merely enable the continuing and ultimately a-rational expansion of appetites.

\section{Why Are We So Hungry?}

It is especially telling that the subject of the appetites that drive the historical process for North - the glutton, the gambler, and the miser - are uncannily familiar to a capitalism based on consumption and lifestyle (gaming/gambling/non-productive risk-taking, unnecessary (even dangerous) consumption, and the persistent collection of stuff). They are forms of recursive consumption that do little but lead to the same kind of consumption. It would indeed be a poor world if we were content with life's necessities, but in the $300+$ years since North, we have become increasingly suspicious, perhaps even anxious, about our persistent dissatisfaction with our own (apparent) abundance. Thus, the glutton, the gambler, and the miser also embody forms of consumption that are also icons of irrationality in our current way of thinking. Indeed, they all slipped easily into sub-categories of "addiction" in the late $20^{\text {th }}$ century - food addict/eating disorder, gambling addict/disorder, and hoarder. At about the same time, addiction becomes a sort of metaphysical epidemic and the undead experience something of a regime change.

In retrospect, the relationship between the undead and the addict looks almost overdetermined - and works such as Susanne Zieger's recent book, Inventing the Addict (2008), examining the vampire and the addict in the $19^{\text {th }}$ century seems almost late in coming (see also Thiher 1973). What gets stressed in these cultural studies (and indeed many philosophical) texts, however, is an almost heroic notion of pleasure (see especially Sedgwick 1994), which, I think is only a partial explanation of our collective fascination with [out-ofcontrol] consumption. A cursory reading of sources expressing anxiety about addiction or 
metaphorically extending the category to environmentally unsustainable consumption are largely silent on the pleasures of consumption. While our appetites can bring us pleasure, they need not necessarily do so, and, if the constituent persons in the golem that is The Leviathan are developing ever more refined appetites in ever increasing quantity, then we start to worry less about the fun that they might be having and more about what they will not (metaphorically at least) eventually consume.

This anxiety explains the metaphorically corrosive quality of addiction that has allowed it to emerge as both optic for, and diagnosis of, a variety of global ills, largely supplanting the use of cancer as the model of malignant growth and "out of control" ruptures in either the economy or the society. The addict, for example, is now understood as a privileged node connecting and amplifying dystopic global circuits in both a material and metaphorical sense - "black markets" for illegal drugs, the ownership and use of illicit weapons, and the accumulation of "dirty" money - meet and proliferate within the appetites of this body and its social activities. We speak of these situations as "breakdowns" as if we do not recognize such recursive consumption as the basis of our own lives and social formation. Yet, at the same time, we continue to increase the scope of that to which a subject can become "addicted" while widening the metaphorical uses of the category (see Denizet-Lewis 2010; for critique see Peele 1989, 2000). In other words, as consumption has become ever more central to our lives and our social formation, its transformations have become ever more complex and the lines between its harmful and healthy expressions are ever more difficult to discern, while its out-of-control varieties become ever more terrifying. The anxieties even terrors of the modern environmental movement then are logically apocalyptic (in the original Greek sense of the word as an 'uncovering').

\section{Zombies Ascendant}

Thus, with the advent of increasingly globalized consumer capitalism, the democratization of expansive appetite emerges as a source of anxiety in its own right. Abundance becomes frightening precisely because it becomes ever more abundant, ever more alienating, and ever less satisfying. Seemingly, as fewer and fewer facets of our being escapes a connection with market-driven consumption, the more anxious we become about the relationships between our appetites, our means, and our ethical effects in the world. How easy it is then to turn the shiny shopping mall - one of America's (and then the rest of the world's) gleaming temples to the seeming defeat of scarcity and the re-visioning everyone as a consumer - into an 
apocalyptic wasteland populated by zombies in Romero's 1978 movie, Dawn of the Dead (Figure 9).

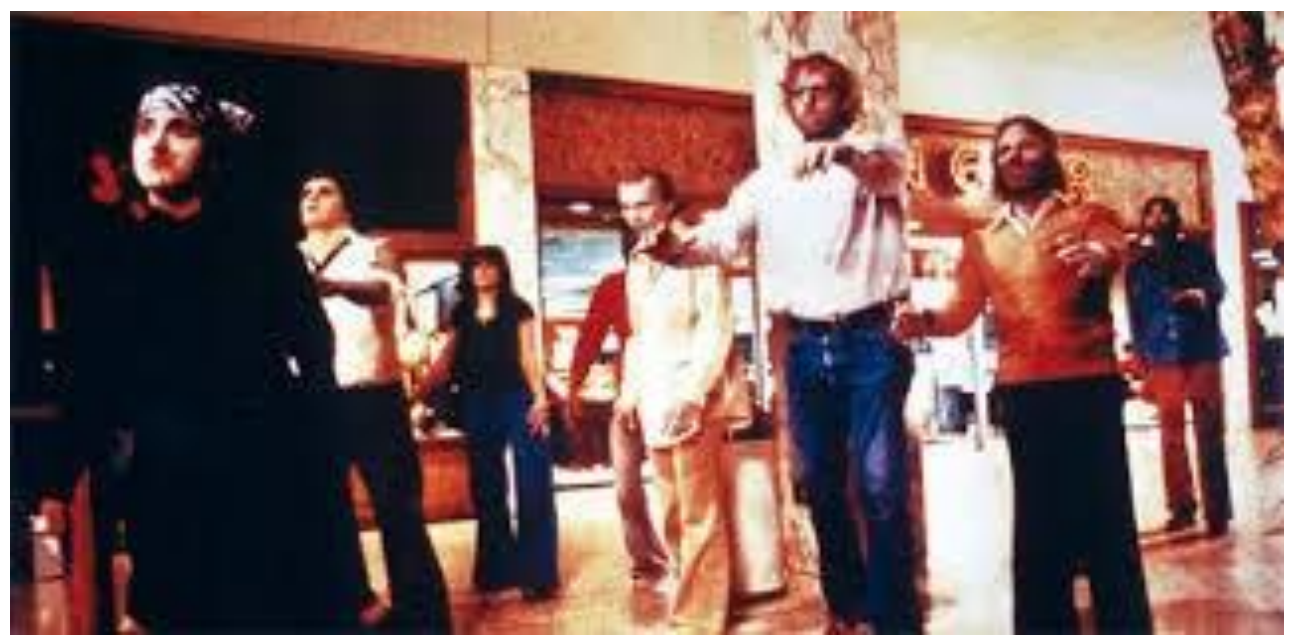

Figure 9: https://www.giornalettismo.com/wp-content/uploads/2013/12/sciagure-di-ogni-natale-4170x90.jpg

Zombies, however, did not begin their folkloric careers either so scary or so apt as a critique consumer society. Ironically, zombies are actually rather dull in most of the properly folkloric stories that we have about them. For much of their history, work, specifically agricultural labor, was the defining feature of the zombiehood. For example, one of the ways that W. B. Seabrook's, in The Magic Island, evidences the presence of zombies is on the rather prosaic basis of hearing people working their gardens in the moonlight (Seabrook 1929, 94; see also Dendle 2007). Only a few years later, zombies make their big screen debut in Vincent Halperin's White Zombie (1932) starring (again) Bela Lugosi in a movie that (while successful enough as a film) was decidedly less profitable (never mind the influence on the popular imagination) than was Dracula. In these and other depictions, powerful Voodoo priests are the real malefactors, and they transform people into zombies less for occult reasons than for personal ones. Even in the odd lurid story involving Zombies sent to kill a priest's enemies, they clearly function as somewhat clumsy, cut-rate assassins, rather than as an occult terror as such (for a somewhat different reading, see Zieger 2013).

Hollywood then pretty much loses interest in this species of the undead for a few decades. George Romero's Night of the Living Dead makes zombies available to Art in two ways. 
First, he produces the basic template for nearly all subsequent zombie narratives - an unspecified toxin or virus gets released (generally by either a government body or a megacorporation which is portrayed as simultaneously evil and clumsy), usually affecting a limited number of people to begin with - but after that point, person-to-person contact spreads zombiehood, in the same way that sneezing on someone spreads the common cold. In this way, acmes of modernity (returning spacecraft to high-tech research) are recast as inherently threatening, and the Enlightenment confidence that increasing knowledge leads inevitably to better lives is directly challenged.

But, the real genius of George Romero flows from his second move, that is, from the profound transformation that he wreaks on the folkloric zombie collective. It is not widely appreciated that Romero is, in many respects, the Margaret Thatcher of Zombieland: overnight, he threw all the zombies out of work, turning them from pathetic and clumsy producers into wholly irrational and clumsy consumers. After Romero, zombies lose any productive function, and it is their massed hunger that becomes the primary source of the horror they invoke. After Night of the Living Dead, zombies were never going back to work their gardens, and the idea of collapse and apocalypse got a new, scary, decomposing face.

In other words, zombies became fit for horror only when they became unproductive and very hungry. In this they became like vampires: they feed on us. What makes zombies and vampires "good to think" resides precisely in how they are articulated to their respective hungers in an ontologically different way than we are connected to ours. To put it as bluntly as possible, the hungers of vampires and zombies have been liberated from the tyranny of the alimentary canal. Their appetites are stimulated, their mouths feed, and swallowing occurs, but with little or no evidence of the passing of what is consumed, save to stimulate the desire to feed again. Appetites, then, lead neither to excrement nor to adipose tissue, they simply, "frictionlessly" call forth more appetite. Nonetheless, the hungers of these species of the undead lead to different end-points. Vampires feed on humans in a recursive way to consciously extend a form of life-in-death. After Romero, on the other hand, zombies are simply hunger without consciousness, conscience, or very much purpose. They are more like embodied appetite than a body with an appetite. Indeed, the zombie is not usually written or depicted as even knowing it is hungry.

It is in this peculiar subjection of zombies to their hunger (in Butler's 1991 sense), however, that renders vampires and humans closer than either of them are to zombies. Both humans and vampires live in the symbolic order. This is what makes possible vampires' anxiety about being alienated from themselves, as their distress at their lack of a reflection in the mirror clearly shows. For humans, though, the emergence of Stoker's vampire template is still in the 
era of the flaneur - it was still possible to see one's reflection in the shop window full of commodities. Ironically, vampires know they are alienated (and are often troubled by this fact) because they are like us in most other respects - not just in the sense of forming social bonds with each other and with humans, but also in understanding and sharing that uniquely human capacity for symbolic thought. They can tell the difference between holy water and regular water - indeed arguably better than we can. ${ }^{14}$ It is this symbolic faculty, however, that ultimately also makes vampires vulnerable. We can imagine beating vampires, and we almost always do. ${ }^{15}$ Zombies, though, are not in the symbolic order. They did not understand their alienation as down-market producers, nor do they understand their alienation as insatiable consumers. They lack even the capacity for alienation, and we increasingly worry that we might be becoming like them. Thus, while the audience might be initially invited to consume "zombies" as Other - the hoi poloi of the undead that are locked into an endless cycle of meaningless repetitive consumption - the new iPhone in our pockets and our next mall visit tells us something rather different.

\section{Conclusion}

It is not an accident that, after Romero's fixing of the modern Zombie narrative, we look upon earlier texts with fresh eyes. The famous passage of the middle-class family-in-a-bubble from Galbraith's Affluent Society, for example, reads eerily current to a culture that seems to almost continuously imagine its individual and social debilitation through out-of-control appetites (addictions), its collective self-destruction through environmental degradation

14 It is a shame that Leslie White in his essay, The Symbol: the Origin and Basis for Human Behavior (1940), did not capitalize on this connection. Human do not just have a unique capacity to understand the difference between Holy Water and regular water, they can also imagine monsters who share this peculiar ability and, for that precise reason, can be defeated by humans.

15 It is telling that going back to Stoker, successful vampire combat is almost always a collective enterprise usually with voluntarily agreed upon hierarchies and a sense of collective ownership of the project, in other words, something like a social contract. Indeed, in Dracula, this collective is expressly sealed with an oath pledging the individual lives of the oath-takers to the liberating of Mrs. Harker's soul from Dracula's baptism of blood. The fight against zombies, on the other hand, comes only after a social collapse and a return to the state of nature. Thus, in most zombie movies, the bonds between the survivors are tenuous, volatile, and the source of most of the dramatic conflict in the narrative. Similarly, the instructions on how to survive a zombie apocalypse encourage a sort of Robinson Crusoe self-sufficiency while there is still time to pull together the resources to survive the coming state of nature. It is not difficult to see a very similar sensibility in the socalled "Prepper Movement" in the United States. 
because of excessive consumption (climate change, the Anthropocene), and its fictional end in a democratic hunger liberated from death itself (a zombie apocalypse).

The family which takes its mauve and cerise, air-conditioned, power-steered and powerbraked automobile out for a tour passes through cities that are badly paved, made hideous by litter, blighted buildings, billboards and posts for wires that should long since have been put underground. They pass on into a countryside that has been rendered largely invisible by commercial art... They picnic on exquisitely packaged food from a portable icebox by a polluted stream and go on to spend the night at a park, which is a menace to public health and morals. Just before dozing off on an air mattress, beneath a nylon tent, amid the stench of decaying refuse, they may reflect vaguely on the curious unevenness of their blessings. Is this, indeed, the American genius? (Galbraith 1958, 187)

Social and environmental degradation and individual consumption are intimately connected here. ${ }^{16}$ Nature is increasingly obliterated and increasingly poisoned, by Culture (perhaps better, Economy-as-Culture), through increasing private consumption feeding ever more refined, ever greater, and ever more popular appetites, which also degrades the social bonds between people. What is lacking in this picture is only an objectifying of appetite itself - the desires and consumption inside the car and the desires and consumption of the (presumably) junkies and sex-fiends that are offending public morals in the park await a connection. In the half century since Affluent Society these have met, first, in an ever-ramifying understanding of addictive appetitive desires, then in an interest in a popular hunger amongst the undead, and, finally, in the metaphorical expansion of "addiction" to model vicious cycles of increased consumption and unsustainable social and environmental degradation.

In short, I believe that in our half-humorous and half-fearful imaginings of a zombie apocalypse and our more serious iteratively expanding discourse about addiction, we have come to the point of seeing a 'magic' in the commodity in a register distinctly derived from Anglophone social theory. This magic is different from the one that Marx found in the transmutation of use value into exchange value, but more dangerous to the idea of the "naturalness of the market" to this body of theory because of its hidden-in-plain-sight quality. In Anglophone Social Theory, "appetitive desire" is the first principle of the creation story of the state and the market (as well as their theoretical inter-relationships) and it is, perhaps, also, the sea of chaos into which the market-state will ultimately dissolve. The curious

16 Richard Tucker (2000) also makes this connection between ever increasing consumption in the developed world leading to the destruction of tropical zones in the Global South. 
subjection of different artistic creations to appetite - appetite that survives death to feed on life - tracks in fiction an evolving and expanding medical-social category in real life, addiction, and an ever-expanding number of addicts who also hunger ceaselessly, supposedly without reckoning cost or consequence. Currently, zombies and addicts are both invited to this bizarre banquet of insatiable appetites and ever-expanding consumption. Our terror comes from a nagging feeling that we, too, might already also be at this gathering. Unfortunately, we currently seem to see little hope after this enforced feast, save an apocalyptic after-dinner floorshow or an uncertain individual recovery.

\section{Acknowledgements}

Foremost, I wish to thank the Internationales Forschungszentrum Kulturwissenschaften for their generous support in my time there as a Senior Fellow in the 2013-14 Academic Year. In particular, I wish to express my warmest gratitude to Scott Spector, Alessia Ricciardi, Erdal Kaynar and Ingo Zechner. My time in Vienna was also very much enriched by interaction with the Department of Anthropology at the University of Vienna. Special thanks go to Thomas Fillitz, Andre Gingrich, Ayşe Çağlar, and Jelena Tosic in this regard. The audience for my public lecture at IFK in January of this year was very engaged, and they raised many points that substantially improved this work. This is also true of other groups to whom I presented this research, The Anthropology Seminar Series in NUI Maynooth and The Organizational Research Cluster in the Department of Anthropology, Stockholm University. I also wish to thank David Slattery, Katja Seidel, Lotar Rasinski, and David Brent for reading earlier drafts. My appreciation goes to Conrad Brunstrom for conversations about pre-Enlightenment uses of the word 'addict'. Special thanks go to Johan Lindquist, Katja Seidel and Fiona Murphy for critical feedback that greatly improved my argument. Finally, I wish to thank the anonymous reviewers of this piece. Any mistakes and omissions are my own. 


\section{References Cited}

Alexander, Bruce. 2008. The Globalization of Addiciton: A Study in Poverty of Spirit. Oxford: Oxford University Press.

Berg, Maxine. 2005. Luxury and Pleasure in Eighteenth-Century Britain. Oxford: Oxford University Press.

Berry, Christopher J. 1994. The Idea of Luxury: A Conceptual and Historical Investigation. Cambridge University Press.

Bumiller, Elizabeth, and Adam Nagourney. 2006. "Bush: America is Addicted to Oil." New York Times website, February 1. Accessed [August 27, 2021]. http://www.nytimes.com/2006/02/01/world/americas/01ihtstate.html?pagewanted=all\&_r=0.

Butler, Judith. 1991. The Psychic Life of Power: Theories in Subjection. Palo Alto: Stanford University Press.

Carson, Rachel. 1962. Silent Spring. Boston: Houghton Mifflin Co.

Comaroff, Jean, and John Comaroff. 2002. "Alien-nation: Zombies, Immigrants and Millennial Capitalism." South Atlantic Quarterly 101 (4): 789-805.

Courtwright, David T. 2001. Forces of Habit: Drugs and the Making of the Modern World. Cambridge, MA: Harvard University Press.

Denizet-Lewis, Benoit. 2010. America Anonymous: Eight Addicts in Search of a Life. New York: Simon \& Schuster.

Dendle, Peter. 2007. "The Zombie as Barometer of Cultural Anxiety." In Monsters and the Monstrous: Myths and Metaphors of Enduring Evil, edited by Niall Scott, 45-57. Amsterdam: Rodophi.

Dole, Vincent P., and Marie E. Nyswander. 1967. "Heroin Addiction - A Metabolic Disease." Archives of Internal Medicine 120: 19-24.

Dole, Vincent P., and Marie E. Nyswander. 1976. "Methadone Maintenance Treatment: A Ten-year Perspective." Journal of the American Medical Association 235: 2117-2119.

Friedman, Thomas L. 2000. The Lexus and the Olive Tree. New York: Anchor Books.

Friedrich, Paul. 1989. "Language, Ideology and Political Economy." American Anthropologist 91 (2): 295-312.

Fukuyama, Francis. 1993. The End of History and the Last Man. New York: Avon Books. Galbraith, James K. 1958. The Affluent Society. Fortieth Anniversery Edition Boston, MA: Houghton Mifflin. 
Goodman, Aviel. 1990. "Addiction: definition and implications." British Journal of Addiction 85: 1403-1408.

Healy, David. 2004. Let Them Eat Prozac: The Unhealthy Relationship Between the Pharmaceutical Industry and Depression. New York: New York University Press.

Hobbes, Thomas. 1651. The Leviathan. Accessed August 27, 2021. https://www.gutenberg.org/files/3207/3207-h/3207-h.htm

James, Susan. 1997. Passion and Action: The Emotions in Seventeenth-Century Philosophy. Oxford: Oxford University Press

Leshner, A. I. 1997. "Addiction Is a Brain Disease, and It Matters." Science. 278 (5335): 45-47.

Lorenz, Hendrik. 2006. The Brute Within: Appetitive Desire in Plato and Aristotle. Oxford: Oxford Philosophical Monographs.

North, Dudley. 1691. Discourses Upon Trade. London: Tho. Basset. Accessed August 27, 2021.https://archive.org/details/sirdudleynortho00nortgoog

O'Reilly, Fiona, and A. Jamie Saris. 2010. A Dizzying Array of Substances: An Ethnographic Study of Drug Use in the Canal Communities. Dublin: The Canal Communities Local Drugs Task Force.

Peele, Stanton. 2000. "What Addiction is and is Not: The Impact of Mistaken Notions of Addiction." Addiction Research 8 (6): 599-607.

Peele, Stanton. 1989. The Diseasing of America: Addiction Treatment Out of Control. Boston, MA.: Houghton Mifflin.

Petryna, Adriana, Andrew Lakoff, and Arthur Kleinman. 2006. Global Pharmaceuticals: Ethics, Markets, Practices. Durham, SC: Duke University Press.

Polidori, John William. 1819. The Vampyre. London: The New Monthly Magazine and Universal Register. Accessed August 27, 2021. http://www.gutenberg.org/ebooks/6087.

Reinhert, Sophus. 2011. Translating Empire: Emulation and the Origins of Political Economy. Cambridge, MA: Harvard University Press.

Sahlins, Marshall. 2008. The Western Illusion of Human Nature, with Reflections on the Long History of Hierarchy and the Sublimation of Anarchy in the West, and Comparative Notes on Other Conceptions of the Human Condition. Chicago: Prickly Paradigm Press.

Sahlins, Marshall. 1976. Culture and Practical Reason. Chicago: University of Chicago Press. 
Sakovich, Roman. 2012. Half. Accessed August 27, 2021. https://www.romansakovich.co.uk/portfolio/half/

Saris, A. Jamie. 2021. "The Dialectics of Heroin and Methadone in Ireland". Irish Journal of Psychological Medicine. First View: 1-7 https://doi.org/10.1017/ipm.2021.52

Saris, A. Jamie. 2013. "Committed to Will: What's at Stake for Anthropology in Addiction." In Addiction Trajectories, edited by Raikhel, Eugene and William Garriot, 263-283. Duram, NC: Duke University Press.

Saris, A. Jamie. 2011. "The Addicted Self and the Pharmaceutical Self: Ecologies of Will, Information, and Power in Junkies, Addicts, and Patients." In The Pharmaceutical Self: The Global Shaping of Experience in an Age of Psychopharmacology, edited by Jenkins, Janice H., 209-230. Santa Fe, NM: School for Advanced Research on the Human Experience (SAR).

Saris, A. Jamie. 2008. "An Uncertain Dominion: Irish Psychiatry, Methadone, and the Treatment of Opiate Abuse." In Special Edition of Culture, Medicine, and Psychiatry, edited by Dominique Behague, 32 (2): 239-257. Accessed [August 27, 2021]. http://eprints.nuim.ie/1125/.

Seabrook, William B. (1989) 1929. The Magic Island. New York: Paragon House.

Sedgwick, Eve K. 1993. "Epidemics of the Will." In Tendencies, edited by Michèle Aina Barale, Jonathan Goldberg, and Michael Moon, 130-142. Durham: Duke University Press.

Shakespeare, William. 1599. Henry IV, Part II. Accessed August 27, 2021. http://shakespeare.mit.edu/1henryiv/full.html

Shell, Ellen. 2003. Fat Wars: The Inside Story of the Obesity Industry. New York: Atlantic Books.

Smith, Adam. 1788. An Inquiry Into the Nature and Causes of the Wealth of Nations. London: W. Strahan and T. Cadell. Accessed August 27, 2021. http://www.gutenberg.org/files/3300/3300-h/3300-h.htm

Stoker, Bram. 1897. Dracula. London: Archibald Constable and Company. Accessed August 27, 2021. http://www.literature.org/authors/stoker-bram/dracula/

Thiher, Alan. 1973. "Le Feu Follet: The Drug Addict as Tragic Hero.” PMLA 88 (1): 3440.

Tucker, Richeard. 2000. Insatiable Appetites: The United States and the Ecological Degradation of the Tropical World. Berkeley: University of California Press. 
van der Geest, Sjaak, Susan R. Whyte, and Anita Hardon. 1996. "The Anthropology of Pharmaceuticals: A Biographical Approach.” Annual Review of Anthropology 25 (1): 153-178.

White, Leslie. 1940. "The Symbol: the Origin and Basis for Human Behaviour." Philosophy of Science 7 (4): 451-463.

Zieger, Susanne. 2013. "The Case of William Seabrook: Documents, Haiti, and the Working Dead." Modernism/Modernity 19 (4): 737-754.

Zieger, Susanne. 2008. Inventing the Addict: Drugs, Race, and Sexuality in NineteenthCentury British and American Literature. Amherst: University of Massachusetts Press.

\section{Movies}

Halperin, Edward. 1932. White Zombie. Accessed August 27, 2021. https://www.youtube.com/watch?v=NV3B2z0HkKA.

Romero, George. 1968. Night of the Living Dead. Accessed August 27, 2021. https://www.youtube.com/watch?v=H91BxkBXttE.

Romero, George. 1978. Dawn of the Dead. Accessed August 27, 2021. https://www.youtube.com/watch?v=BbcU-qW7Zvo.

\section{Videocasts}

Volkov, Nora. 2006. Addiction: A Disease of Free Will. Accessed August 27, 2021. https://www.youtube.com/watch?v=X1AEvkWxbLE 
A. Jamie Saris is an Associate Professor in the Department of Anthropology, NUI Maynooth. He holds advanced degrees in Social-Cultural Anthropology from the University of Chicago (MA and $\mathrm{PhD}$ ), and he has completed a Postdoctoral Fellowship in Clinically-Relevant Medical Anthropology in the Department of Social Medicine, Harvard Medical School. He has been working for more than twentyfive years in medical and psychological anthropology in Ireland, North America, and parts of Africa, where he has researched and made significant contributions to understanding such diverse issues as the social life of mental hospitals, colonialism and its aftermath, health

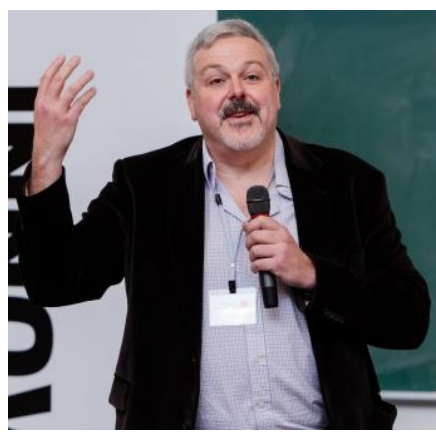
services research, drug use and abuse, HIV risk and treatment and Patient-Centred Care. He sits of the Editorial Boards of Culture, Medicine, and Psychiatry and Reviews in Anthropology, and he was the Editor of The Irish Journal of Anthropology from 1995-2006. He was also the Co-Chair of the Combat Diseases of Poverty Consortium, funded under The Programme of Strategic Cooperation between Irish Aid and Higher Education and Research Institutes 2007-2012, and served as the Deputy Director of National Institute of Regional and Spatial Analysis (NIRSA), a multi-disciplinary research centre of excellence examining space and society. 